\title{
EL CONCEPTO DE DEMOCRACIA DE LA CONSTITUCIÓN DE WEIMAR ${ }^{1}$
}

\section{THE CONCEPT OF DEMOCRACY IN THE WEIMAR CON- STITUTION}

\author{
Gertrude Lübbe-Wolff \\ Universidad de Bielefeld
}

\begin{abstract}
SUMARIO. I. EL PRELUDIO DE LA DEMOCRACIA WEIMARIANA: LOS TRABAJOS DE LA ASAMBLEA NACIONAL.- II. EL ORDEN DEMOCRÁTICO DE LA CONSTITUCIÓN DE WEIMAR.- 2.1. El derecho electoral democrático.- 2.2. La forma de gobierno semiparlamentaria.- 2.2.1. La dependencia del gobierno de la confianza del parlamento.- 2.2.2. La función legislativa del Parlamento.- 2.2.3. El estatuto de los diputados.- 2.2.4. Los pasos hacia un „ejército parlamentario“ y hacia la democratización del poder exterior.- 2.3. Partidos y asociaciones.- 2.4. Mecanismos de democracia directa.- 2.5. El Presidente del Reich como „contrapeso“ del Parlamento.- 2.6. La posibilidad de leyes de habilitación.- 2.7. Intentos de defensa de los presupuestos del orden democrático.- 2. 7.1. Estado de derecho, derechos fundamentales y justicia constitucional.- III. CONCLUSIÓN.
\end{abstract}

Resumen. La Constitución de la República de Weimar fue progresista y prometedora en muchos aspectos. Previó a medias un sistema parlamentario, un derecho del Parlamento a controlar al gobierno, pero atribuyó al Presidente del Reich la facultad de elegir y nombrar al canciller, al que le correspondia también el poder de disolver el parlamento a su antojo, e importantes poderes excepcionales. Los deméritos de ese diseño, para el que Hugo Preuß, el redactor de la Constitución de Weimar, se había basado en una teoria del parlamentarismo desarrollada por el jurista alsaciano Robert Redslob, contribuyeron al fracaso final de la Constitución. Los mecanismos de democracia directa, a menudo criticados, desde luego, no lo hicieron. Los principales motivos por los que fracasó la primera democracia de Alemania son totalmente ajenos a la Constitución.

\begin{abstract}
The constitution of the Weimar Republic was progressive and promisinng in many respects. However, it established parliamentarism only half way, with a parliamentary right to overtrow government, but with the right to select and appoint the chancellor in the hands of the president, who could also dissolve parliament at wish, and had extensive emergency powers. The demerits of that design, for which Hugo Preuß, the drafter of the Weimar constitution, had relied on a theory of parliamentarism developed by the alsatian jurist Robert Redslob, contributed to the eventual failure of the constitution, whereas the oft-blamed

\footnotetext{
1 Una versión más extensa de este trabajo ha sido originalmente publicada en $\mathrm{H}$. Dreier $\mathrm{y}$ C.
} Waldhoff (edits.), Das Wagnis der Demokratie: Eine Anatomie der Weimarer Reichsverfassung, ed. CH. Beck, München, 2018. Traducción de Leonardo Álvarez Álvarez, Profesor de Derecho Constitucional de la Universidad de Oviedo.
\end{abstract}


instruments of direct democracy did not. The main reasons why the first Geman democracy failed are fully external to the constitution.

Palabras clave. Sistema electoral, parlamentarismo, partidos políticos, democracia directa, presidencialismo, Estado de derecho.

Keywords. Electoral system, parliamentarism, parties, direct democracy, presidentialism, rule of law

La Constitución del Imperio alemán de 1871, tras su aprobación por el Bundesrat y el Reichstag, proclamó con gran énfasis en su preámbulo: „Guillermo, Emperador alemán por la gracia de Dios, Rey de Prusia“. A eso siguió algo dificil de leer, que no consiguió captar la atención de nadie. Ello implicaba, desde luego, una gran diferencia respecto de la futura Constitución de Weimar de 1919 que afirmaría „el Pueblo alemán [...] se ha dado esta Constitución“. Esta proclamación vertida en el preámbulo evidenciaba que la nueva Constitución se diferenciaba esencialmente de la del año 1871 al hacer descansar el fundamento de su legitimidad en el demos, en el pueblo. Esto se expresaría en el primer párrafo de su art. 1,1: „El poder del Estado emana del pueblo“. La Constitución de Weimar no solo tuvo un objeto, sino un espíritu ciertamente democrático. La democracia debía ser el fundamento y la predeterminación de todo lo posterior.

\section{EL PRELUDIO DE LA DEMOCRACIA WEIMARIANA: LOS TRABAJOS DE LA ASAMBLEA NACIONAL}

Cuando la Asamblea Nacional constituyente se reunió en Weimar el 6 de febrero de 1919, ya se había tomado de facto una de las más importantes decisiones sobre la estructura de la Constitución: que el futuro orden no se sustentaria ya en un sistema de consejos, como el modelo soviético (sowjet=ruso: consejo), esto es, en una organización jerarquizada de delegados vinculada por las órdenes de la nueva clase dominante. Se optó, en su lugar, por una democracia parlamentaria. En diciembre de 1918, el Congreso de trabajadores y de soldados del Reich habia aprobado la convocatoria de una Asamblea Nacional constituyente, rechazando la moción de que se debía asegurar la permanencia del sistema de consejos como fundamento de la Constitución venidera. En consecuencia, „el sistema de consejos fue rechazado por los propios consejos“"2.

En la Asamblea Nacional, los partidos mantuvieron la posición de rechazar la República en todo o en parte y el tránsito hacia una democracia parlamentaria sin asegurar los objetivos políticos económicos y militares socialistas. El escepticismo sobre la democracia en sí y la madurez del pueblo respecto de ella, y sobre el propio sistema de partidos, que sustituía el modelo de notables por los partidos del pueblo, fue muy extendido. En amplios sectores del espectro de partidos burgueses, la monarquía se despidió a la fuerza y con importantes reservas internas.

2 Gerhard Anschütz, Die Verfassung des Deutschen Reichs vom 11. August 1919. Ein Kommentar für Wissenschaft und Praxis, 14 edición, Berlin 1933, pág. 14. 
Los métodos de trabajo de la Asamblea Nacional y sus resultados evidenciaron que las condiciones para un satisfactorio funcionamiento del proceso democrático parlamentario habian faltado, en realidad, desde el principio. A pesar de ello, el proceso en el interior del Parlamento reflejó su potencial integrador sobre todo en el acuerdo general suscrito por los diputados sobre cuestiones de fondo. La cooperación y el compromiso definieron el trabajo cotidiano de la Asamblea, más que las posiciones unilaterales, los reproches recíprocos y la polarización. Muchas controversias originarias fueron finalmente aprobadas sin votos en contra. Hubo coaliciones de voto entre Gobierno y oposición. También numerosas muestras de voluntad de cooperar para alcanzar acuerdos viables en aras del interés general, también de respeto, de afinidad personal o de simpatía al margen de las incompatibilidades políticas existentes. El teórico del Estado Gerhard Anschütz señaló que los trabajos de la Asamblea Constituyente se habían caracterizado por la objetividad y por la minuciosidad, y por „el carácter pacífico del comportamiento de las partes entre sí, algo que se había convertido cada vez más en una rareza en la vida parlamentaria“. Gertrud Bäumer (DDP), alli presente, recordaba que en ocasiones había surgido alli „algo parecido a un leal grupo de trabajo“. 3

Sin embargo, la Constitución de Weimar fracasó en la tarea más importante a la que se enfrenta cualquier Constitución, y a la que justamente la democracia parece hallarse más vinculada: la de integrar a los ciudadanos en una unidad política de convivencia. Ese fue, en realidad, el caso de muchas Constituciones europeas del periodo de entreguerras. Sin embargo, „Weimar“ fue la quintaesencia de dicho fracaso. No solo por el naufragio de un orden democrático en sí digno de conservar, sino porque lo que vino después fue manifiestamente espantoso. Es cierto que probablemente el concepto de democracia no fuese especialmente adecuado. La pregunta que debe de formularse es en qué medida ello pudo haber contribuido a que la primera democracia alemana durara tan poco.

\section{EL ORDEN DEMOCRÁTICO DE LA CONSTITUCIÓN DE WEIMAR}

\subsection{El derecho electoral democrático}

La Constitución de la Confederación del Norte de Alemania de 1867 y la Constitución de 1871 reconocieron elecciones „generales“. Sin embargo, las mujeres, como por entonces se consideró con gran naturalidad, todavía no se contaban entre dicha "generalidad“. Esto cambió con la revolución de noviembre de 1918. El sistema electoral diseñado para la elección de la Asamblea Nacional constituyente exteriorizó el cambio revolucionario en el concepto demos, al declarar expresamente que „todos los hombres y mujeres“ tienen derecho al voto al cumplir los 20 años. ${ }^{4}$. Esto se plasmó también en la Constitución de Weimar (art.

3 Anschütz, Verfassung (nota. 2), pág. 27; Gertrud Bäumer, Lebensweg durch eine Zeitenwende, Tübingen 1933, pág. 380. Sobre el modo de trabajo principalmente cooperativo de la Asamblea Nacional véase en particular Thomas Mergel, Parlamentarische Kultur in der Weimarer Republik. Politische Kommunikation, symbolische Politik und Öffentlichkeit im Reichstag, Düsseldorf 2012, pág. 47 y ss.

4 Decreto sobre las elecciones a las Asamblea Nacional constituyente alemana (Ley electoral del Reich), de 30 de Noviembre de 1918, RGB1. 1918, pág. 1345, § 2. 
22,1), marcando una diferencia respecto de la época Imperial en la que, a pesar de haber rebajado la mayoria de edad electoral, se había fijado en 25 años.

Otro cambio importante en comparación con la situación jurídica existente bajo la Constitución precedente residió en la apuesta constitucional por una elección proporcional (Art. 22,1 WRV). Este sistema electoral reforzó a los partidos-especialmente a partir de que la ley se decantó por un sistema de listas cerradas y bloqueadas-- y favoreció la conversión del Reichstag en un parlamento funcional. Ello no favoreció, sin embargo, la construcción de gobiernos estables. Se puede incluso dudar de si la decisión de la democracia de Weimar en contra de un sistema electoral mayoritario hubiera sido favorable, a pesar de que el sistema electoral proporcional, al menos en su efecto más directo, es tendencialmente más integrador. También los críticos atribuyeron y aún atribuyen al sistema electoral de Weimar una escasa eficacia sobre la prevención de conflictos en la fase postrevolucionaria. ${ }^{5}$

\subsection{La forma de gobierno semiparlamentaria}

\subsubsection{La dependencia del gobierno de la confianza del parlamento}

Ya en las últimas etapas del Imperio, con las así denominadas reformas de octubre de 1918, la Constitución de 1871 fue objeto de reforma, exigiendo que el canciller -nombrado posteriormente por el Kaiser--necesitara de la confianza del Reichstag y fuera responsable ante éste. La mayoria necesaria obtenida en favor de este paso hacia el parlamentarismo no obedeció, desde luego, a la difusión de convicciones democráticas, sino a la previsible derrota en la guerra, para cuya superación, sobre todo para los previsibles tratados de paz, se requería un gobierno apoyado en el parlamento.

Hugo Preuß (DDP) fue uno de los que estuvo trabajando desde hacía tiempo sobre una reforma constitucional de estas características, no solo motivado por la derrota militar. Fue precisamente Preuß quien elaboraría el primer borrador de la Constitución de Weimar a solicitud de Friedrich Ebert. En el argumentario de Preuß en favor de la necesidad de una parlamentarización del sistema de gobierno tuvo especial relevancia la cuestión sobre la formación y la elección de los dirigentes politicos adecuados. Un parlamento dotado de la capacidad para formar gobierno llevaria a los políticos presentes en el Parlamento con cualidades de liderazgo al órgano gubernamental, en vez de a simples funcionarios sin adscripción política. El pueblo alemán podría, así, finalmente „encontrar a su ansiado y fuerte líder políti-

\footnotetext{
5 Cfr. sobre la polémica en la socialdemocracia Axel Misch, Das Wahlsystem zwischen Theorie und Taktik. Zur Frage der Mehrheitswahl und Verhältniswahl in der Programmatik der Sozialdemokratie bis 1933, Berlin 1974, pág. 129 y ss., 224 y ss. et passim. En favor de la aceptación de un irrenunciable efecto polarizador durante la fase de posguerra Martin Martiny, Parlamentarismus und innerparteiliche Demokratie: Die Diskussion um die Ausgestaltung des Wahlrechts, en: idem., Integration oder Konfrontation? Studien zur Geschichte der sozialdemokratischen Rechtsund Verfassungspolitik, Bonn-Bad Godesberg 1976, pág. 13-53 (26 y ss.), con ulteriores consideraciones.
} 
co“. ${ }^{6}$ Esto se correspondía con la por entonces primacía del interés político en la „selección de líderes“, también difundida entre los democrátas.

La Constitución de Weimar, en la articulación jurídica de la dependencia del Gobierno de la confianza del Parlamento, siguió finalmente el modelo de octubre de 1918 y las propuestas de Hugo Preuß. De conformidad con ellas, solo atribuyó al Parlamento una influencia vinculante sobre el gobierno a través de la manifestación de su desconfianza. Una elección parlamentaria u otra expresión positiva de confianza por parte del Parlamento, al igual que antes, no se requería para la formación de Gobierno (véase el Art. 53 WRV). La dependencia del gobierno de la confianza del Reichstag proclamada en el texto constitucional (Art. 54 Abs. $1 \mathrm{WRV}$ ) era, por tanto, en esencia, solo una dependencia en tanto el Reichstag no expresara su desconfianza. Esto permitió con frecuencia gobiernos en minoria y durante la fase final de la República incluso gabinetes presidenciales impuestos frente al Parlamento.

Más allá de la confianza parlamentaria que la Constitución de Weimar exigía, el Gobierno necesitaba también de la confianza del Jefe del Estado. Su nombramiento y su permanencia en el cargo dependia de ella. Al igual que el Kaiser durante la vigencia de la Constitución Imperial de 1871, también el Presidente del Reich en la Constitución de Weimar podía cesar al canciller y a los ministros. (Art. $53 \mathrm{WRV}$ ). Tras ésta y otras competencias del Presidente del Reich se encontraba un concepto de parlamentarismo más próximo a la monarquía constitucional que a la democracia (véase infra 5).

\subsubsection{La función legislativa del Parlamento}

El Parlamento, prima facie, en ejercicio de su función legislativa, fue considerablemente reforzado por la Constitución de Weimar. Hugo Preuß describió clara y concisamente los positivos cambios sustanciales experimentados en tal sentido: „hasta el momento, la participación del Reichstag en la función de dirección politica estaba limitada, en esencia, a la crítica y a la negación; podía impedir, pero apenas orientar positivamente. En la legislación solo sus decisiones de rechazo eran plenamente eficaces. La iniciativa atribuída formalmente al Reichstag podía convertirse en ineficaz a través del rechazo o del silencio del Bundesrat [...] Ahora el Reichstag es el verdadero y decisivo legislador, al margen del referéndum. El Reichsrat solo tiene frente a él un veto suspensivo; el Presidente del Reich y el Gobierno solo pueden intervenir en él a través de su disolución o, bajo determinadas circunstancias, mediante la llamada a la decisión popular."7

La valoración acerca de que con la facultad de disolución, la interferencia del Presidente del Reich y del Gobierno sobre el trabajo del parlamento presentaba una „escasa“ entidad, se mostró equivocada.

${ }^{6}$ Hugo Preuß, Freiheit und Macht (1917), en: idem., Gesammelte Schriften, vol. 1, Politik und Gesellschaft im Kaiserreich, editado por Lothar Albertin/Christoph Müller, Tübingen 2007, pág. 675-678 (678).

7 Hugo Preuß, Deutschlands Staatsumwälzung. Die verfassungsmäßigen Grundlagen der deutschen Republik (1919), en: idem, Gesammelte Schriften, vol. 4 (nota 6), pág. 101-113 (107). 
Al Presidente del Reich se le atribuía además, como también al Kaiser, la función de promulgar y de sancionar las leyes (Art. 70 WRV). Esto abarcaba una competencia de control de su constitucionalidad - cuyo alcance jurídico fue discutido-- que fue reiteradamente utilizada para negar la promulgación y la sanción presidencial. ${ }^{8}$ La posibilidad apuntada por Preuß de apelar al pueblo contra una decisión legislativa mediante la convocatoria de un referéndum (Art. 73 Abs. 1, 4 WRV ) no fue utilizada en la práctica. Con ello no se dice nada acerca del más importante efecto de cualquier ejercicio de poder-el condicionamiento del comportamiento de los actores potencialmente ejercientes del mismo. Finalmente, el Presidente del Reich podia ocupar el espacio del legislador a través de los decretos de excepción (más en concreto sobre ello infra 5).

La facultad de aprobar los presupuestos fue competencia del Parlamento ya durante la vigencia de la Constitución de la Confederación del Norte de 1867 y de la Constitución Imperial de 1871. Sin embargo, tal facultad experimentó una importante restricción bajo la Constitución de Weimar, como lo demostró al menos en la práctica, el hecho de que no se encontrara fuera del alcance de los decretos de excepción. Sobre todo durante los últimos años de vigencia de la Constitución de Weimar la competencia presupuestaria se incluyó dentro del margen de actuación de aquellos decretos, que llegaron incluso hasta la completa sustitución de la ley de presupuestos. ${ }^{9}$

\subsubsection{El estatuto de los diputados}

Con similares palabras a las empleadas en la Constitución Imperial de 1871 y en la actualidad la Ley Fundamental, la Constitución de Weimar reconoció la prohibición del mandato imperativo de los representantes del pueblo: „Los diputados son representantes de todo el pueblo. No están sometidos a órdenes y se encuentran solo vinculados a su propia conciencia“ (Art. 21 WRV). De esta manera, la Constitución de Weimar rechazó el mandato imperativo característico de la democacia de consejos y optó por un mandato representativo. A pesar de esta ausencia de subordinación jurídica, la parcial parlamentarización de la forma de gobierno hizo surgir la necesidad de una disciplina partidista, al convertirse los diputados en un apoyo confiable del Gobierno sostenido por su partido. El necesario cambio que ello produjo de la percepción de los parlamentarios como una oposición frente $a$, los de ahí arriba“ hacia una imagen basada en la contraposición entre el compromiso sustentado en una mayoría de gobierno y la oposición minoritaria no tuvo el suficiente éxito como para generar relaciones estables. Las coaliciones de apoyo al gobierno existieron mucho antes que las mayorias de partidos radicales que trabajaron en direcciones contrapuestas hacia la revolución, haciéndolas completamente imposibles. O no surgieron o no lo hicieron con la suficiente viabilidad, y la disciplina de partido dejó mucho que desear.

\footnotetext{
8 Anschütz, Verfassung (nota. 2), Art. 70 marg. 2.

9 Sobre ello Christoph Gusy, Die Weimarer Reichsverfassung, Tübingen 1997, pág. 250 con ulteriores consideraciones.
} 
Ello no fue solo el resultado de actitudes anacrónicas impropias de un sistema parlamentario, sino también de la decisión, por la inexperiencia política, de haber optado por un sistema constitucional semiparlamentario, que descansaba sobre todo en las funciones de liderazgo presidencial y gubernamenal. Como resultado, el Parlamento se vio dispensado de la necesidad de ejercer sus funciones.

A la ya extendida atmósfera antiparlamentaria contribuyó el hecho de que la prohibición de mandato imperativo de los diputados del Reichstag se viera comprometido de diferentes maneras. Los partidos, entre ellos, los comunistas, que fueron desde principio reacios a la prohibición del mandato imperativo, lo socavaron exigiendo a sus diputados in spe estipulaciones de renuncia de su escaño en caso de eventuales desviaciones de la línea de partido. ${ }^{10}$ Además, numerosos parlamentarios no solo percibian sus correspondientes dietas, sino que se encontraron al servicio de grupos de interés, en ocasiones incluso profesionalmente. ${ }^{11}$

El modelo de parlamento de notables en el que los diputados podian permitirse el ejercicio no remunerado de su cargo, había comenzado a abandonarse durante la época imperial. La prohibión prevista en la Constitución de que los diputados percibieran un sueldo o una compensación fue modificada en 1906 por una ley del Reich que preveía el pago de una remuneración establecida. La Constitución de Weimar asumió este modelo y confirió tambien rango constitucional al derecho antes contemplado en la ley de viajar gratuitamente (Art. 40 WRV). Las burlas y los odiosos comentarios a las dietas de los parlamentarios fueron virulentas, no solo en los círculos antirepublicanos y antiparlamentarios. ${ }^{12} \mathrm{El}$ acuerdo sobre las dietas adecuadas con el argumento de que solo así podían acceder al Parlamento todos los sectores de población sin depender de remuneraciones de los grupos de interés, fue difícil en vista del gran número de diputados que al mismo tiempo prestaban sus servicios a dichos grupos.

A pesar del pago de dietas, el ejercicio la función parlamentaria no fue en la Constitución de Weimar una actividad obligatoria profesional y tampoco fue percibida así mayoritariamente. Durante un tiempo así se reconoció también durante la vigencia de la actual Ley Fundamental. La continuidad de las labores profesionales ejercidas con anterioridad fue frecuente entre los diputados del Reichstag, lo que trajo consigo conflictos de intereses que se resolvieron a expensas del

10 Nikolaus Urban, Die Diätenfrage. Zum Abgeordnetenbild in Staatsrechtslehre und Politik 1900-1933, Tübingen 2003, pág. 125 y s., 161. Sobre la continuidad de esta práctica aún durante la vigencia de la Ley Fundamental, véase Thomas Saalfeld, Parteisoldaten und Rebellen. Fraktionen im Deutschen Bundestag 1949-1990, Wiesbaden 2013, pág. 46 y la nota 31; Klemens Kremer, Der Abgeordnete. Zwischen Entscheidungsfreiheit und Parteidisziplin, München 1956, pág. 50 .

11 Urban, Diätenfrage (nota. 10), pág. 125 y s.; Mergel, Parlamentarische Kultur (nota. 3), pág. 98 y ss. (101).

12 Sobre la historia de la indemnización parlamentaria véase Hermann Butzer, Diäten und Freifahrt im Deutschen Reichstag. Der Weg zum Entschädigungsgesetz von 1906 und die Nachwirkungen dieser Regelung bis in die Zeit des Grundgesetzes, Düsseldorf 1999, pág. 373 y ss., 391 y s., 401 y ss.; Urban, Diätenfrage (nota. 10), pág. 93 y ss., 125 y s., 131 y s., 140 y ss., 147. 
mandato parlamentario. También estuvieron ausentes otros presupuestos necesarios para el adecuado ejercicio de las funciones del Parlamento. Walther Lambach, que ocupó un escaño en el Reichstag por el Deutschnationale Volkspartei (DNVP), describió la organización y los métodos de trabajo del Reichstag en un libro que merece la pena leer titulado „Die Herrschaft der Fünfhundert“ („el poder de los quinientos“). En él se narran los intentos del novato imaginario MüllerHinterwalden de orientar y de encontrar su rol dentro del Parlamento. MüllerHinterwalden constató que, además de un gimnasio y de una barbería, existía un archivo y una biblioteca, a los que podian acceder los diputados. Para los partidos, también una „oficina con varias mujeres“. Al servicio de los diputados, aparte de las secretarias y el servicio de correos, no existiría ningún colaborador ni personal auxiliar y en los despachos, que tuvo que compartir con cinco colegas y las secretarias, habia menos lugares de trabajo que diputados. ${ }^{13}$

Al estatuto de los diputados, no solo desde la Constitución de Weimar, pertenecía además la prerrogativa de la inmunidad (Art. $37 \mathrm{WRV).} \mathrm{Sin} \mathrm{embargo,} \mathrm{ésta}$ fracasó una y otra vez, también en el momento decisivo. La ley de plenos poderes de 24 de enero de 1933 fue aprobada por el Reichstag después de que la totalidad de los diputados comunistas-- en tanto no hubieran huído o hubiesen sido deportados-- y varios socialdemócratas, fueran detenidos en manifiesta violación de su inmunidad.

\subsubsection{Los pasos hacia un "ejército parlamentario“ y hacia la democratiza- ción del poder exterior}

La Constitución de Weimar dio algunos pasos -algunos ya esbozados en las reformas de octubre del año 1918-en favor de un „ejército parlamentario“. El control parlamentario sobre el ejército y las fuerzas armadas, en general, ya habia sido discutido durante la época imperial. Esto se produjo, entre otras cosas, con el reconocimiento de la facultad atribuida al Parlamento de declarar la guerra y hacer la paz, un elemento nuclear de control sobre la intervención de las fuerzas armadas: „La declaración de la guerra y de la paz han de acordarse mediante una ley del Reich“ (Art. 45 Abs. 2 WRV).

La competencia para declarar la paz debía de ejercerse en la práctica inmediatamente. Incluso antes de la entrada en vigor de la Constitución de Weimar, conforme a lo previsto en la Ley sobre el poder provisional del Reich, correspondía aprobar el Tratado de Versalles como ley. La declaración de la paz no había sido anteriormente un privilegio atribuido únicamente Kaiser. Durante la época imperial no hubo un supuesto similar al Tratado de Versalles. Representaba una novedad que ya no se requiriera solo la autorización parlamentaria a la negociación realizada previamente por el ejecutivo. El poder legislativo, como pusiera de manifiesto Gerhard Anschütz, „aparece no solo como una de las partes en la aprobación, sino como el señor mismo de la cuestión. "14 El hecho de que la parlamenta-

13 Walther Lambach, Die Herrschaft der Fünfhundert, Hamburg-Berlin 1926, pág. 87 y ss., 91 y s., sobre las obligaciones contrapuestas idem, pág. 94, 107 y s.

14 Anschütz, Verfassung (nota 2), Art. 45 marg. 5. 
rización convirtiera al Parlamento, en cierto modo, en el autor del catastrófico tratado de paz, fue y sigue siendo una pesada carga para la República de Weimar.

Además de los tratados que afectaran a las reservas de ley, la Constitución de Weimar sometió por primera vez a la necesaria aprobación del Reichstag la celebración de alianzas, es decir, los acuerdos de apoyo entre los Estados en caso de guerra. (Art. 45 Abs. 3 WRV).

La inclusión de las fuerzas armadas en la estructura democrática de la República permaneció, sin embargo, jurídicamente incompleta-muy alejada de la creación de un auténtico "ejército parlamentario“-y resultó fácticamente poco exitosa.

El ejército siguó siendo un núcleo central de poder independiente. La Constitución atribuyó su mando supremo al Presidente del Reich (Art. 47 WRV). Disponía además, expresamente, que también en „el ámbito militar“ todas las órdenes y disposiciones del Presidente del Reich deben de estar refrendadas por los miembros del gobierno (Art. 50 S. 1 WRV). Por ello, los actos de mando del ejército entraban dentro del objeto de su responsabilidad parlamentaria. También este paso hacia la parlamentarización tuvo efectivamente un efecto limitado en tanto el Gobierno y el Parlamento dependian respectivamente del cese o de la disolución del Presidente del Reich. La Constitución de Weimar, más allá de las previsiones relativas a las labores centralizadas y a la jurisdicción militar, no contenía disposiciones específicas sobre la renovación organizativa y personal de las fuerzas armadas.

A pesar de la discontinuidad formal, no se llevaron a cabo importantes reformas sobre el encuadre político del ejército en el Estado democrático. La Constitución garantizó a los soldados profesionales el carácter inviolable de sus derechos adquiridos (Art. 129. 4 frase 1) y se conformó para asegurar su lealtad a la Constitución con imponer el requisito de que los miembros del ejército prestasen juramento a "esta“ Constitución (Art. 176 S. 1 WRV). Que la ley negara a los integrantes de las fuerzas armadas el derecho de sufragio activo no contribuyó a su integración en el orden democrático, sino más bien a fortalecer la autocomprensión de los militares como una dimensión superior a la política.

Desde un punto de vista fáctico no tuvo éxito ni el intento de sumar al ejército a la causa de la república democrática ni la necesidad de afrontar desde una perspectiva democrática su desmovilización tras el final de la guerra con la reducción del ejército a 100.000 hombres impuesta por el Tratado de Versalles.

La liberación del ejército, entre ellos cientos de miles de soldados profesionales, muchos de los cuales no se dejaron integrar fácilmente en la vida civil, hizo que se diseminaran en grupos paramilitares. Grupos que, más tarde, con "el frente en la sangre" y amargados por los "criminales de noviembre" que culpaban de haber instaurado la República y firmado el contrato de Versalles, desestabilizaron el Estado mediante golpes de estado y asesinatos. Tanto el gobierno revolucionario como los gobiernos posteriores dependieron del ejército y de los cuerpos de voluntarios, así como de otras asociaciones militares, para luchar contra los movimientos comunistas y otros revolucionarios de izquierdas. La propia Asamblea Nacional estuvo defendida por un cuerpo de voluntarios. También se recurrió a 
unidades irregulares para la defensa de la frontera del este. Las concesiones a los militares no pudieron asegurar su lealtad. Cuando se trató de defender la democracia frente a los ataques de la derecha, no se pudo contar con el ejército. El cese del General v. Lüttwitz por insubordinación derivó en el golpe de estado Kapp-Lüttwitz. No hubo apoyo militar por parte del ejército al gobierno del Reich. Sólo una huelga general salvó, por el momento, la República. El armamento secreto suministrado sorteando el Tratado de Versalles y la financiación subrepticia al margen del presupuesto ubicaron a los gobiernos en una complicidad ilegal con el ejército. Con ello se aumentó considerablemente el potencial antidemocrático de la violencia, lo que contribuyó fundamentalmente a la presencia permanente de formas antidemocráticas e incivicas de enfrentamiento y al final llevaron a los Nacionalsocialistas al poder. ${ }^{15}$

Las loables intenciones de evitar retornar a las tradiciones belicistas manifestadas en el preámbulo de la Constitución de Weimar en nombre del pueblo alemán („inspirado en la voluntad de contribuir [...] a la paz interior y exterior“) se vio privada del suficiente apoyo institucional y no pudo ser eficaz por sí misma. Las imposiciones del Tratado de Versalles de eliminar el servicio militar obligatorio y de reducción del ejército tuvieron un efecto contraproducente como, en general, todo el Tratado de Versalles, que fue percibido como humillante. El mandato educativo impuesto en el art. 148,1 de la Constitución que obligaba a las escuelas „a promover la formación moral, el sentimiento cívico, las aptitudes personales y profesionales en el espíritu de la cultura y de la reconciliación alemanas“ no pudo hacer nada en su contra. Gerhard Anschütz, el más destacado comentarista de la Constitución de Weimar, en la penúltima edición de su comentario, veía en esta obligación educativa en el espíritu de reconciliación, todavía en 1930, „una obligación moral contra toda persona de mentalidad nacionalista, ya sea profesor o estudiante“. 16

\subsection{Partidos y asociaciones}

Los partidos políticos solo se mencionaron en una disposición de la CW, en la que se determinó que los funcionarios están obligados a „servir al interés general, no a un partido" (Art. $130 \mathrm{WRV}$ ). No hubo una regulación positiva de sus funciones, como sucedería más adelante con la Ley Fundamental. Tampoco existieron disposiciones constitucionales como las hoy reguladas en la Constitución vigente relativas a la exigencia de una estructura democrática interna en los partidos, a la rendición pública de cuentas sobre destino de sus medios ni prescripciones sobre las condiciones para la prohibición de partidos políticos.

15 Sobre la financiación armamentístiva secreta al margen del presupuesto del Parlamento Rüdiger Bergien, Die bellizistische Republik. Wehrkonsens und „Wehrhaftmachung“ in Deutschland 1918-1933, München 2012, pág. 107 y ss., 112 y ss., 125 y ss., 175 y ss.; Andreas Dietz, Das Primat der Politik in kaiserlicher Armee, Reichswehr, Wehrmacht und Bundeswehr, Tübingen 2011, pág. 272 y ss.; Patrick Oliver Heinemann, Rechtsgeschichte der Reichswehr 1918-1933, Paderborn 2018, pág. 54 y ss.

16 Gerhard Anschütz, Die Verfassung des deutschen Reichs vom 11. August 1919, 13ª edición, Berlin 1930, Art. 148 marg. 2 (pág. 594). Esta apreciación no se encuentra en la decimocuarta edición de 1933 (nota 2). 
Que la Constitución de Weimar no previera una prohibición de partidos antisistema no significó que tal prohibición no hubiera sido posible, sino solo que la misma no se sometía a las limitaciones hoy prefijadas en el art. 21 de la Ley Fundamental. La democracia de Weimar no se encontraba constitucionalmente indefensa frente a sus enemigos, contrariamente a lo que, sobre todo, Carl Schmitt afirmó. Para la prohibición definitiva de las organizaciones nazis no faltaron en el Estado mecanismos legales, sino solo la voluntad política.

No pudo encontrarse en la Constitución de Weimar una disposición expresa relativa al concepto o a la función de los partidos políticos. Sin embargo, pudo inferirse una decisión clara y consciente en favor de una democracia basada en la competencia entre diferentes partidos libremente constituidos. La Constitución de Weimar garantizó el derecho a constituir sociedades y asociaciones (Art. 124 WRV), y con ello, la libertad para crear partidos y grupos de interés. Separadamente se reguló la libertad de asociación de los empresarios y sindicatos y sus funciones consistentes de negociar los salarios y las condiciones laborales (Art. 159 WRV, Art. 165 Abs. 1 WRV).

Con todas estas previsiones, y con la garantía de un sistema electoral libre e igualitario, se rechazaron claramente las posiciones difundidas, sobre todo, entre los ambientes burgueses de la derecha, de construir la representación popular y de regular de las relaciones empresariales y laborales desde un punto de vista corporativo. Este rechazo fue confirmado a través de una minima concesión hacia tales postulados que, al mismo tiempo, verbalizó el rechazo a la idea de una democracia de consejos: el mandato dirigido al legislador para la creación de un consejo económico del Reich (véase Art. 165 párrafos 2-6 de la Constitución). Tal mandato, como era de esperar, se reveló en la práctica como intrascendente.

Lo que institucionalizó la Constitución de Weimar fue lo que se denominó por sus enemigos como una „democracia de recuento“, 17 en la que los partidos se convirtieron necesariamente en catalizadores de la construción de la voluntad política. Además, a que la democracia pluralista de partidos encontrara un amplio rechazo contribuyó la inclinación difundida en Alemania -- por oposición a las formas tradiciones occidentales organizativas y de pensamiento-- hacia lo directamente comunitario, no basada en formas de intermediación de intereses libres y contrapuestos. También desempeñó un papel importante la ausencia de familiaridad de los partidos y de la sociedad con la construcción de compromisos y con las alianzas para apoyar continuamente un gobierno común, impuesta por la instaurada parlamentarización, especialmente bajo un sistema de representación proporcional. Bajo la Constitución Imperial de 1871, los partidos pudieron pasar por alto en gran medida tanto los dogmatismos como la disciplina de partido sin un evidente perjuicio para sí mismos. El gobierno, sin cuyo concurso no era posible la legislación, no dependía de ello. Sin embargo, bajo las nuevas circunstancias, que exigian de los partidos tanto la disposición a formar compromisos como la disciplina de partido, el acatamiento o no de dichas exigencias dependieron de la preferencia material del observador. La primera fue tan infrecuente como oportunista, la segunda, expresión de la caótica ausencia de li-

17 Véase Edgar Tatarin-Tarnheyden, Kopfzahldemokratie, organische Demokratie und Oberhausproblem, en: Zeitschrift für Politik 15 (1926), pág. 97-122. 
derazgo. Aunque uno se haya acostumbrado a ello, estas expectativas contradictorias han seguido inspirando la democracia de partidos hasta la actualidad.

La influencia de los grupos de interés adoptaron diversas formas en el Reichstag. „Los síndicos de todos los grupos industriales se encuentran presentes entre los usuarios permanentes de la alfombra roja de los vestíbulos del Reichstag“ escribió Walther Lambach, ${ }^{18}$ con lo que fueron claramente visibles. Los grupos de interés no solo se manifestaron en las conversaciones y en los diferentes encuentros, sino que también desempeñaron un importante rol en la financiación de los partidos, de los parlamentarios y de otros políticos. Entre los diputados se encontraban, como se ha señalado, muchos integrantes de asociaciones, especialmente representantes de agrupaciones empresariales, incluidas asociaciones agricolas y sindicatos. Entre otras influencias directas de las asociaciones empresariales y de sus fondos electorales, fue frecuente en la práctica la confección de las listas de sus representantes y los contratos celebrados con los diputados, en los que se comprometían a ejercer su mandato en favor del interés de los proveedores de fondos y a suministrarles información de su interés. ${ }^{19}$ Aunque es cierto que los grupos de interés intensificaron sobre todo su actuación en el Reichstag, su principal destinatario seguía siendo, ante todo, el ejecutivo. Ello incluyó al Presidente del Reich. Es conocido el regalo de una finca señorial a Hindenburg por su 80 cumpleaños en 1927, financiada por los círculos industriales y agrarios del Elba oriental. Carl Duisberg, Presidente de la Asociación de la Industria alemana, entregó la escritura de la donación el día de la recepción organizada con ocasión del cumpleaños de Hindenburg. ${ }^{20}$

Max Weber había definido como una "tarea fundamental de la democracia“ romper la "corruptora influencia politica“ que habian tenido sobre el antiguo régimen los „señores de la industria pesada“. ${ }^{21}$ No se tomó nota de ello. La Constitución de Weimar no incluyó disposiciones para limitarla, para promover la igualdad de oportunidades o, al menos, la garantía de transparencia en referencia a tales influencias. Se limitó a proclamar la independencia de los diputados y a garantizar el derecho de petición (Art. 126 WRV). Es verdad que la vigente Ley Fundamental no fue mucho más lejos.

18 Lambach, Herrschaft (nota 13), pág. 78.

19 Karl-Heinz Adams, Parteienfinanzierung in Deutschland. Entwicklung der Einnahmestrukturen politischer Parteien oder eine Sittengeschichte über Parteien, Geld und Macht, Marburg 2005, pág. 24 y ss. (28 y s.).

20 Annika Klein, Korruption und Korruptionsskandale in der Weimarer Republik, Göttingen 2014, pág. 450 y ss. ff. Sobre la incidencia de intereses organizados en la figura del Presidente del Reich, véase también Seog-Yun Song, Politische Parteien und Verbände in der Verfassungsrechtslehre der Weimarer Republik, Berlin 1996, pág. 102 y s.

21 Max Weber, Deutschlands künftige Staatsform (1919), en: Wolfgang J. Mommsen/Wolfgang Schwentker (edits.), Max Weber, Zur Neuordnung Deutschlands. Schriften und Reden 1918-1920 (Max Weber Gesamtausgabe parte I, vol 16), Tübingen 1988, pág. 98-146 (115). 


\subsection{Mecanismos de democracia directa}

La democracia de Weimar estuvo fuertemente inspirada por elementos „plebiscitarios“. Con frecuencia se ha entendido como su máxima expresión la reforzada posición „plebiscitaria“ del Presidente de la Reich, directamente elegido por el pueblo. En otras ocasiones, el concepto de plebiscito se ha entendido, quizás más acertadamente, como alusivo solo a las decisiones materiales adoptadas por el pueblo, dejando al margen las vinculadas con la elección o el cese de personas. Independientemente de uno y otro concepto, se tratará aquí de las decisiones directas adoptadas por el pueblo en los supuestos previstos en la Constitución.

Con ello, la Constitución compatibilizó los mecanismos de democracia directa con el sistema democrático representativo propio de la legislación. Ello afectaba, entre otras materias, a las reestructuraciones del territorio (art. $18 \mathrm{CW}$ ). Solo para esta finalidad la Constitución previó una decisión popular. La Constitución de Weimar fue, sin embargo, mucho más allá. No solo se preveía la posibilidad de apelar al pueblo a través de los órganos del Estado, sobre todo por parte del Presidente del Reich, que podía someter a su decisión cualquier ley aprobada por el Reichstag (Art. 73 Abs. 1 WRV). ${ }^{22}$ También se reconoció la iniciativa de referéndum a los ciudadanos con derecho a voto, que podia tener por objeto una ley aprobada por el parlamento (Art. 73 Abs. 2, Art. $75 \mathrm{WRV}$ ). Incluso iniciativas legislativas parlamentarias (Art. 73 Abs. $3 \mathrm{WRV}$ ). Sin embargo, en materia financiera la confianza en el pueblo era limitada. Se excluyeron las iniciativas de referéndum sobre los presupuestos, las leyes tributarias y salariales. La posibilidad de adoptar decisiones populares sobre dichas materias se atribuyó en exclusiva a la iniciativa del Presidente del Reich (Art. 73 Abs. 4 WRV). Sin embargo, las posibilidades de una decisión democrática directa se vieron seriamente limitadas por el elevado quórum de participación previsto. Era necesaria la participación de la mayoría de los ciudadanos con derecho a voto (véase el art. $75 \mathrm{CW}$ que, conforme a la opinión mayoritaria, era aplicable a todos los supuestos de la legislación).

Hasta hoy en día ha sido objeto de discusión si la combinación de la democracia parlamentaria-representativa con los mecanismos decisorios de la democracia directa contribuyó al naufragio de la Constitución de Weimar. Contrariamente al parecer del pasado, más recientemente cada vez un numero mayor de voces han negado este aspecto. El análisis de los resultados de la democracia directa no ofrece, de hecho, ninguna base para una valoración crítica al respecto. En la mayoría de los casos no se cumplió siquiera el diez por ciento requerido para celebrar un referéndum a iniciativa de los electores. En ningún caso la iniciativa popular tuvo éxito finalmente. La crítica respecto a la mezcla de los elementos democrático-representativos y „plebiscitarios“ fue vertida principalmente en abstracto o se llevó a cabo sin una necesaria diferenciación con el rol cualificado plebiscitario del Presidente del Reich. ${ }^{23}$ En lo que se refiere, en particular, a los procedimientos democráticos directos fue críticamente valorado el referéndum

22 Véase además sobre determinados supuestos de conflicto entre el Reichstag y el Reichsrat Art. 74 Abs. 3 und Art. 76 Abs. 2 WRV.

23 Véase, por ejemplo, Ernst Fraenkel, Deutschland und die westlichen Demokratien, $4^{\mathrm{a}}$ edición, Stuttgart y otros, 1968, pág. 112 y ss. 
sobre la expropiación a los Príncipes (1926) y sobre el Plan Young, relativo al pago de las reparaciones impuestas por el Tratado de Versalles (1929). El „estímulo“ que habria supuesto el agresivo referéndum auspiciado por el NSDAP contra el Plan Young había contribuido, como afirmara por ejemplo Karl R. Newman, a que las masas apoliticas se aproximaran a los nacionalsocialistas, que consiguieron transformar las elecciones parlamentarias en plebiscitos, extendiéndose „también a las elecciones de los Länder, de los municipios, e incluso de los sindicatos".24 $\mathrm{Si}$, de este modo, los „plebiscitos“ se convierten en un concepto que abarca los procesos decisorios con participación popular basados en la polarización y en la radicalidad, la tesis acerca de la tendencia hacia la polarización y la radicalidad de los procesos de democracia directa se convierte manifiestamente en una tautología.

Puede plantearse la pregunta de si precisamente una mayor democracia directa no hubiera podido dispensar una mejor defensa de la Constitución democrática. Según el proyecto de Constitución de Hugo Preuß, de 3 de enero de 1919, caracterizado por escasos elementos de democracia directa, las reformas constitucionales tras una inicial fase transitoria de cinco años solo hubiera sido posible con la ratificación por vía de referéndum. ${ }^{25}$ En la Asamblea Nacional el SPD habia propuesto un referéndum constitucional obligatorio. ${ }^{26}$ Ante una previsión de estas características, las sucesivas reformas constitucionales a través de leyes parlamentarias hubiera sido más dificil. Si hoy día se achaca a la presencia de efectivas posibilidades decisorias de la democracia directa, con frecuencia desde una perspectiva crítica, haber fomentado que los partidos se pusieran de acuerdo en evitar referéndums („democracia de concordancia“), habria que concluirse que en el plano de la simple legislación rebajar las exigencias impuestas por el elevado quorum de participación, habría contribuido a la pacificación.

La opinión predominante durante la posguerra, de hacer corresponsables a los mecanismos de democracia directa de la conversión de la democracia weimariana en una dictatura, ha sido la expresión de un intento de las élites de hacer

24 Karl R. Newman, Zerstörung und Selbstzerstörung der Demokratie. Europa 1918-1933, Köln-Berlin 1965, pág. 159 y ss., citas textuales pág. 160, 162.

25 Véase Anteproyecto/Proyecto I de la Constitución de Weimar: Entwurf des allgemeinen Teils der künftigen Reichsverfassung (3. Januar 1919), en: Preuß, Gesammelte Schriften, vol. 3 (nota 6), pág. 533-540, § 45 parágrafo 2 . Sobre ello y sobre la restrictiva introducción de elementos de democracia directa en este proyecto, véase Hugo Preuß, Denkschrift zum Verfassungsentwurf (3./20. Enero 1919), ibidem., pág. 134-153 (149 y s.). La misma regulación se contiene también en el proyecto II, de 20.1.1919, ibidem., pág. 541-548, § 51 párrafo 1 frase 2; que había sido omitida en el proyecto III de 17 de febrero de 1919, ibidem. pág. 549-560, véase. §§ 52 y 54. Como proyecto del Gobierno en la Asamblea Nacional solo se presentó el proyecto IV de 21.2.1919, idem., pág. 561-573, después de que Walter Jellinek lo hubiera definido como „Proyecto gubernamental II“, véase. Christoph Müller, Erläuterungen, ibidem., pág. 677-718 (700). Sólo el proyecto I, al que se refería originalmente el memorando adjunto, se publicó oficialmente junto con el proyecto II, véase Müller, ibidem., pág. 716, con ulteriores consideraciones-, es un producto genuino de Preuß, cfr. Detlef Lehnert/Dian Schefold, Einleitung, ibidem, pág. 1-78 (18). Las modificaciones en los proyectos II y IV son el resultado de procesos de votación que precedieron a su presentación.

26 Sobre ello Christopher Schwieger, Volksgesetzgebung in Deutschland. Der wissenschaftliche Umgang mit plebiszitärer Gesetzgebung auf Reichs- und Bundesebene in Weimarer Republik, Drittem Reich und Bundesrepublik Deutschland (1919-2002), Berlin 2005, pág. 37. 
responsable al pueblo de haber puesto en peligro la democracia y el Estado de derecho y en ningún modo a ellos. Theodor Heuss, el primer Presidente de la República Federal de Alemania, durante las deliberaciones sobre la Ley Fundamental, rechazó, como es conocido, los referéndums a gran escala en el territorio nacional, que serian un „premio para todos los demagogos“. Sin embargo, los pasos decisivos hacia la toma del poder por parte del mayor demagogo durante de la República de Weimar no fueron dados por la vía de la democracia directa. Fue Theodor Heuss, no en calidad de miembro del pueblo, sino como diputado del Reich-bajo unas condiciones democráticas poco efectivas--, quien votó, en contra de sus propias reservas, en favor de la Ley de Habilitación de 24 de marzo de 1933, lo que contribuyó a la fáctica derogación de la Constitución de Weimar.

\subsection{E1 Presidente del Reich como „contrapeso“ del Parlamento}

La construcción más peculiar de la Constitución de Weimar y la menos previsible en lo que se refiere a sus resultados fue la institución del Presidente del Reich.

De acuerdo con la concepción mantenida por Preuß „el nombramiento del canciller y, de acuerdo con éste, el de los demás miembros del gobierno sería [...] la más importante función del Presidente del Reich“. Que esta función debiera de corresponder al Presidente del Reich en vez de al Parlamento, Preuß la defendió a partir de una mirada a Suiza. En Suiza, el sistema de elección del gobierno a través del Parlamento tenía sus ventajas. Reducía las posibilidades de „un gobierno partidista unilateral [...] porque el colegio gubernamental estaba edificado sobre un compromiso entre los diferentes partidos, de acuerdo con su relación de fuerza aproximada. Así fluía pacífica y tranquilamente toda la vida política“. Sin embargo, en las relaciones de „un gran Estado que necesita de un gobierno capaz de actuar a través de una homogeneidad politica cerrada“, aquello tiene sus desventajas. Un Presidente elegido por el pueblo, en el momento de formar gobierno podría considerar una „pluralidad“ de elementos políticos y técnicos. En estas condiciones, „sería posible sopesar y decidir de una manera más efectiva que a través de una elección parlamentaria directa“. Una elección del Presidente de la República a través del parlamento, como sucedía en Francia, no sería compatible con el „verdadero parlamentarismo“. Éste exigiría la elección directa por el pueblo; dado que el mismo presupone „dos órganos superiores en el Estado ubicados esencialmente en una posición de paridad“. Es decir, una igualdad entre Parlamento y Presidente, que sólo puede edificar una elección popular. En el caso de que se suscitaran conflictos irresolubles entre el Presidente y el Parlamento, en la medida en que su poder político derivaba del pueblo, la decisión debería de recaer en éste. Por ello, el Presidente estaría autorizado, a través de la disolución del Parlamento a „presentar a la representación popular directamente ante el pueblo“ o en caso de una ley en concreto, someter el correspondiente conflicto a un referéndum. Por otra parte, en conflictos especialmente graves, el Parlamento tendria la competencia para convocar un referéndum sobre la continuidad del Presidente. Ello se somete a la „responsabilidad politica del Parlamento“. ${ }^{27}$

\footnotetext{
27 Preuß, Denkschrift zum Verfassungsentwurf (nota 25), pág. 146, 148 y s.
} 
Hoy día sorprende que la orientación hacia el compromiso que Preuß percibió en Suiza por la disposición de partidos minoritarios innecesarios a formar parte del gobierno, la identificara, sin más, con una falta de firmeza. También que pusiera a Alemania en la tesitura de tener que optar entre una gran tranquilidad de la vida politica y la capacidad de eficacia de su gobierno, decantándose por la última sin un argumento convincente.

Preuss no pareció haber reparado en que la competencia para formar gobierno del Presidente del Reich no tendría mucha utilidad en el sistema electoral proporcional previsto, mientras el Parlamento estuviese dispuesto a conformar la mayoria necesaria, en tanto el especto de partidos decidieran no confiar en una dictadura del Presidente del Reich. Precisamente a él y a su partido, el DDP, les irritó especialmente que una vez los grupos parlamentarios y los partidos politicos decidieran tomaran las riendas, la disposición a la formación de coaliciones no solo dependió de una unidad sobre un programa político común, sino (quién lo hubiera pensado!) también de la consideración de sus opiniones sobre los ministros. Para Hugo Preuß esto fue una usurpación de la competencia para formar gobierno, que la Constitución había confiado al Presidente del Reich. Respecto de ello, afirmó que: „los necesarios contactos del Presidente del Reich con el Reichstag para averiguar quién podría obtener su confianza, no debe de degenerar en que los grupos políticos se distribuyan las carteras entre sí y elijan a los ministros, [...] Eso no es parlamentarisno, sino una caricatura“.28 Friedrich Ebert pudo experimentarlo cuando sus planes se vieron fracasados. Los intentos de su propio partido de persuadir a Wilhelm Cuno de aceptar el encargo de Ebert de formar gobierno, se concibió como una amenaza para el parlamentarismo. Ebert se reunió, entretanto, con los representantes de otros grupos parlamentarios y consiguió que Cuno eligiera a su propio equipo de gobierno. ${ }^{29} \mathrm{Si}$ tales circunstancias implicaron que el sistema de gobierno semiparlamentario no fuera propicio para la formación de gobiernos estables, quedaba fuera de su alcance.

Que la injerencia parlamentaria en la formación de gobierno fuera contraria al parlamentarismo fue defendida por el teórico del Estado y del derecho internacional alsaciano Robert Redslob. Esta concepción del parlamentarismo impregnó la concepción de Hugo Preuss sobre la Constitución de Weimar y también ésta misma. ${ }^{30} \mathrm{El}$ diseño de la figura del Presidente del Reich en la Constitución de

28 Preuß, Republikanische Reichsverfassung, pág. 342; véase también del mismo autor, Staatsumwälzung (nota 7), pág. 110. Crítico en similares términos Theodor Heuss, Demokratie und Parlamentarismus, ihre Geschichte, ihre Gegner und ihre Zukunft, en: Anton Erkelenz (edit.), Zehn Jahre deutsche Republik. Ein Handbuch für republikanische Politik, Berlin 1928, pág. 98117 (111).

29 Más en concreto Raithel, Parlamentarismus. 180 y s.. En la construcción de los gobiernos precedentes el Parlamento tuvo ciertamente una influencia decisiva, dado que el equilibrio de poder entre los órganos constitucionales dependía en gran medida de la mayoría parlamentaria. Véase sobre la práctica de edificación de los gobiernos Hans Dietrich Krause-Harder, Die Praxis der Regierungsbildung im Reich, Diss. jur. Königsberg 1931, pág. 20 y ss., 46 y ss.

30 Robert Redslob, Die parlamentarische Regierung in ihrer wahren und in ihrer unechten Form. Eine vergleichende Studie über die Verfassungen von England, Belgien, Ungarn, Schweden und Frankreich, Tübingen 1918, pág. 1-8, así como la soberanía del pueblo erigida en el rol de árbitro pág. 180 y s. Críticamente al respecto véase Armel Le Divellec, Robert Redslobs Theorie des Parlamentarismus. Eine einflussreiche verfasssungsvergleichende „Irrlehre“?, en: Detlef Lehnert 
Weimar, en sus aspectos esenciales, permaneció cercana a la concepción del primer proyecto de Preuß.

Es cierto que la facultad del Presidente del Reich de devolver las leyes aprobadas fue suprimida antes de la remisión del proyecto a la Asamblea Nacional. El mandato del Presidente, como originariamente habia propuesto Preuß, tampoco se fijó en 10 años -el doble de la duración prevista para el mandato parlamentario-, sino en 7 (Art. 43 S. $1 \mathrm{WRV}$ ), mientras que el mandato parlamentario quedó reducido a 4 años en vez de los 5 propuestos por Preuß (Art. 23 S. 1 WRV). Sin embargo, permanecieron inalterados los elementos esenciales de la construcción de Preuß: la elección popular del Presidente del Reich (Art. 41 WRV), su reelección ilimitada (Art. 43 Abs. 1 Satz 2 WRV), el refrendo de sus decretos y de sus disposiciones (Art. 50 S. $1 \mathrm{WRV}$ ), la facultad para el nombramiento y el cese del canciller y de los ministros del Reich, a propuesta de éste, (Art. 53 WRV), el derecho a la disolución del Parlamento solo una vez por el mismo motivo, sin que fuera necesaria, como Preuß había previsto, una previa decisión de la Cámara de los Länder. De este modo, la decisión del Presidente del Reich fue libre, como previamente lo había sido la del Kaiser (Art. 25 WRV). También se previó en la Constitución la concepción del Presidente del Reich como el mando supremo de las fuerzas armadas (Art. $47 \mathrm{WRV}$ ) y por último, aunque no menos importante, un amplio derecho de excepción (Art. 48 WRV).

Las facultades de excepción abarcaron el supuesto de que un Land no cumpliese las obligaciones impuestas por la Constitución o por las leyes del Reich, pudiendo incluso actuar con ayuda de la fuerza armada (la denominada ejecución federal). También se reconoció la intervención armada en caso de que se produjera una grave amenaza o un menoscabo contra el orden y la seguridad públicas, pudiendo además, ante tales circunstancias, adoptar „las medidas necesarias para reinstaurar el orden y la seguridad públicas".

La facultad sobre la ejecución federal fue mucho más allá de la reconocida al Kaiser durante la vigencia de la Constitución de 1871, en la que se contemplaba una ejecución previamente acordada por el Reichsrat en caso de incumplimiento de las obligaciones federales por parte de un Land (Art. 19 RV 1871).

Con la extensiva regulación del derecho de excepción del art. 48 CW se sustituyó la limitada facultad del Kaiser para declarar la guerra, sometida a la previa decisión del Parlamento. El art. 48,2 CW suprimió la necesidad de cualquier autorización parlamentaria. La competencia imperial, a falta de prescripciones concretas, fue limitada por la Ley de Prusia sobre el Estado de sitio y circunscrita a los casos de guerra y de rebelión y carecía, por tanto, de facultades para aprobar decretos legislativos. El art. $48 \mathrm{CW}$ no solo fue mucho más lejos, sino que además fue objeto de una interpretación extraordinariamente amplia. ${ }^{31}$

(edit.), Verfassungsdenker. Deutschland und Österreich 1870-1970, Berlin 2017, pág. 107-138 con ulteriores consideraciones.

31 Sobre el derecho de excepción del Art. 48 Abs. 2 WRV véase Julius Hatschek, Deutsches und Preußisches Staatsrecht, vol. II, $2^{a}$ edición, Berlin 1930, pág. 184 y ss., 187 („Una garantía contra el abuso de poder solo la proporciona la responsabilidad ministerial"). En favor de una discrecionalidad no controlable respecto a la necesidad de las medidas aprobadas por el Presidente del Reich, RGSt 57, 384 (385); 65, 364 (365). 
Jamás se aprobó la ley prevista en el art. 48,5 CW que hubiera limitado los poderes excepcionales del Presidente del Reich y podria haber puesto fin a la aprobación de decretos legislativos de excepción como remedio universal para sustituir a la legislación. Ya con el primer Presidente del Reich, Friedrich Ebert (SPD), que en los primeros años de su presidencia se ocupaba también de presidir las reuniones del gabinete, desde 1919 hasta 1925 se hizo uso hasta en 113 ocasiones de los poderes excepcionales. Las consecuencias potencialmente ruinosas que podia acarrear la interpretación y la aplicación extensiva de los poderes de excepción en el caso de que éstos recayeran alguna vez en personas menos leales con la Constitución, aparentemente no fueron perceptibles ni para los actores políticos ni para los observadores. Ello fue un ejemplo de la fatal ausencia de una concepción sobre las instituciones, que fue acompañada por la autoimagen alemana diseñada mediante la cultura, en vez de a través la civilización, mediante los valores internos en vez de las condiciones externas. ${ }^{32}$ Después de una pausa en los años posteriores debido a la relativa consolidación de la economía y de la política, durante los últimos años de la República, Hindenburg y sus gabinetes se aprovecharon de la aplicación práctica de los poderes de excepción para erigirla en un instrumento de dictadura presidencial no dependiente del Parlamento.

En aspectos importantes, los poderes excepcionales de la $\mathrm{CW}$ fueron mucho más allá de lo que habían previsto en un primero momento los proyectos de Preuß. En el texto constitucional, el derecho de excepción estaba ligado expresamente a la facultad suspender en todo o en parte determinados derechos fundamentales. Además, ya no se requería la exigencia prevista por Preuß de que las medidas adoptadas para reinstaurar el orden y la seguridad pública debieran de ser aprobadas por el Reichstag. En su lugar, solo se contempló la obligación del Presidente del Reich de poner inmediatamente en conocimiento del Reichstag las medidas adoptadas, pudiendo éste exigir su derogación.

Esta renuncia a la previa aprobación parlamentaria parecía a primera vista estar a adaptada a un contexto en el que el Parlamento estuviese dominado por alas extremistas y reacias al compromiso y, por lo tanto, no estuviesen en la situación de afrontar una defensa efectiva de la Constitución frente a los posibles peligros. Posiblemente tampoco brindar la autorización necesaria a la aplicación de los poderes de excepción. Sin embargo, para la adecuada valoración de la eficacia de las normas jurídicas, una segunda observación suele ser más fiable que la primera. La segunda observación va más allá de las consecuencias jurídicas contempladas por la norma ante un determinado supuesto de hecho. Se centra sobre todo en analizar el modo en el que los destinatarios y los afectados por las normas acomodan su comportamiento a la existencia de las mismas. Desde esta perspectiva, la supresión del requisito de la autorización parlamentaria debió tener un efecto desfavorable. Esta configuración de los poderes del Presidente del Reich para poder hacer frente eficazmente a toda una constelación de circunstancias excepcionales, dispensó a los grupos presentes en el parlamento de la presión de formar mayorias. Especialmente aquellos que esperaron que la

32 Acerca de esta autoimagen, véase Gertrude Lübbe-Wolff, Die Aktualität der Hegelschen Rechtsphilosophie, en: Birgit Sandkaulen/Volker Gerhardt (edits.), Gestalten des Bewusstseins, Genealogisches Denken im Kontext Hegels, Hamburg 2009, pág. 328-349 (343 y ss.). 
dictadura del Presidente del Reich materializara sus objetivos politicos, renunciaron a construir compromisos parlamentarios. Las circunstancias discurrian hacia sus objetivos, de todos modos.

La facultad del Reichstag a exigir la derogación de los decretos de excepción se mostró en la práctica como un arma poco contundente, ya que el poder del Presidente para disolver el Reichstag fue interpretado de una manera tal, que podía ejercerse aún después de solicitada tal derogación o incluso para anticiparse a la misma. ${ }^{33}$ Así sucedió también en la práctica. Ya la primera disolución del Reichstag decretada en marzo de 1924 por parte del Presidente Ebert se vinculó a los debates parlamentarios suscitados sobre la necesidad de exigir la derogación de los decretos de excepción que tanto el Canciller como el Presidente del Reich consideraron necesarios. ${ }^{34}$ Después de que el 18 de julio de 1930, el Reichstag solicitó la derogación de dos decretos, el Presidente Hindenburg, a instancia del Canciller Brünning, lo disolvió el mismo día mediante decreto. ${ }^{35}$ La política de exigencia de derogaciones del Reichstag fue seguida por nuevos decretos de excepción. Por decreto de 4 de junio de 1932 fue disuelto el Reichstag, porque existía „el peligro“ de que requiriera la derogación de los decretos presidenciales aprobados unos dias antes. ${ }^{36}$

\subsection{La posibilidad de leyes de habilitación}

La función legislativa del Reichstag no solo fue menoscabada por los decretos de excepción aprobados sobre la base de la voluntad conjunta del Presidente y del Gobierno.

Ello se llevó a cabo también en gran medida a través de leyes de habilitación, conforme a lo cual la Asamblea Nacional, ya durante los primeros años de la República, se vinculó a un modelo proclamado en 1914 al inicio de la guerra. La nefasta ley de habilitación de 24 de marzo de 1933 fue solo la última de ellas, sin precedentes en lo que se refiere a su alcance en la cadena de rupturas constitucionales-sin una modificación constitucional en forma de ley de reforma constitucional--. ${ }^{37}$

33 Véase sobre el primer caso Anschütz, Verfassung (nota 2), Art. 48 Anm. 18 b), c); Richard Thoma, Die Notverordnung des Reichspräsidenten vom 26. Juli 1930, en: Zeitschrift für öffentliches Recht 11 (1931), pág. 12-33 (14 y s.).

34 Decreto del Presidente del Reich sobre la disolución del Reichstag, de 13 de marzo de 1924, RGB1. I pág. 173. El motivo de la disolución fue tambien exteriorizado en el propio decreto.

35 Decreto del Presidente del Reich sobre la disolución del Reichstag, de 18 de julio de 1930, RGB1. I pág. 299. Con la disolución del Reichstag se respondió a su resistencia al fundamento de las leyes de autorización de 13 de octubre y de 8 de diciembre de 1923 que autorizaban la aprobación de decretos del gobierno. Véase también el decreto del Presidente, de disolución del Reichstag, de 13 de marzo de 1924, RGB1. I pág. 173.

36 Decreto del Presidente del Reich sobre la disolución del Reichstag, de 4 de junio de 1932, RGB1. I pág. 441.

37 Al respecto Michael Frehse, Ermächtigungsgesetzgebung im Deutschen Reich, Pfaffenweiler 1985; Christoph Gusy, Ermächtigungsgesetzgebung in Deutschland zwischen Verfassungsgefährdung, Verfassungserhaltung und Verfassungszerstörung, en: Zeitschrift für Neuere Rechtsge- 


\subsection{Intentos de defensa de los presupuestos del orden democrático}

\section{7.1. Estado de derecho, derechos fundamentales y justicia constitucional}

La democracia se basa en la igualdad de posiciones de todos los ciudadanos. Como autodeterminación política colectiva solo es posible sobre los presupuestos de una autodeterminación individual. De igual manera, la democracia es solo posible sobre la base y a través de reglas jurídicas. A la democracia pertenecen además la igualdad jurídica, la libertad y el Estado de derecho.

Todos estos elementos se integraron en el concepto de democracia en Weimar. Las disposiciones sobre los derechos fundamentales, que de ninguna manera tuvieron solo el carácter de normas programáticas, garantizaron a los ciudadanos la igualdad y la libertad. ${ }^{38}$ La división de poderes, institucionalizada constitucionalmente, se plasmó en la independencia judicial, la prohibición de los tribunales de excepción, en la obligación de supresión de la jurisdicción militar, excepto en tiempos de guerra y a bordo de buques de guerra, y prescribió la existencia de tribunales administrativos en el ámbito del Reich y los Länder para la tutela del individuo frente a normas y disposiciones de las autoridades administrativas.

Sin embargo, el Estado de derecho reconocido sobre el papel no funcionó en la práctica en aspectos decisivos. Ello fue una de las grandes hipotecas que lastraron la Constitución de Weimar. La no persecución o la indulgencia del todo inapropiada de numerosos asesinatos politicos de la derecha no fue muestra de una justicia sobrecargada, sino en gran medida de una labor judicial parcial y partidista, cuyas acciones y omisiones representaron una labor de formento de la anarquía de la extrema derecha. En los trabajos contemporáneos de Emil Julius Gumbel se ha documentado de la siguiente manera.

La revolución de noviembre había dado a luz „una nueva Constitución, pero no una nueva justicia“.39 Tampoco una nueva administración. Es conocido el hecho de que la asociación alemana de jueces estuviera presidida por una persona para quien las „leyes de compromiso“ de la democracia parlamentaria representaban „mezclas e intersecciones de los intereses de los partidos dominantes, [...] derecho bastardo“, y no reparaba en hacerlo público. ${ }^{40}$

No existió durante la vigencia de la Constitución de Weimar una justicia constitucional que dispensara una tutela jurisdiccional a las reglas de juego de la democracia. Particularmente no hubo ningún tribunal constitucional especializado al que se le atribuyera expresamente una competencia para el control de la constitucionalidad de las leyes y de otros actos jurídicos. Las funciones típicas de la justicia constitucional fueron, sin embargo, disgregadas en diferentes ámbitos

schichte 39 (2017), pág. 246-273. Sobre las consecuencias previstas en la Ley Fundamental, Waldhoff, Folgen - Lehren - Rezeptionen.

38 Más en detenimiento Horst Dreier, Grundrechtsrepublik Weimar.

39 Christoph Gusy, Weimar - die wehrlose Republik? Verfassungsschutzrecht und Verfassungsschutz in der Weimarer Republik, Tübingen 1991, pág. 309. Acerca de la continuidad de las élites, veáse Monika Wienfort, Alte Eliten in der neuen Republik.

40 Johannes Leeb, Dreierlei, en: Deutsche Richterzeitung 13 (1921), pág. 130-131 (131). 
del sistema judicial. Los tribunales del Reich, como anteriormente las cortes supremas de diferentes Länder, se atribuyeron a sí mismos y a los órganos judiciales, la competencia para el control de constitucionalidad de las leyes del Reich -una competencia que fue, por entonces, defendida más por los opositores que por los defensores de la democracia. ${ }^{41}$ Sin embargo, como es característico de los tribunales dotados de la competencia para el control de la constitucionalidad de la ley, esta función se ejerció con gran cautela durante los primeros años.

El tribunal electoral creado „por el Reichstag“, integrado por miembros del propio Reichstag y del Tribunal administrativo del Reich o, en la medida en que fracasó su creación, el Reichgericht (Art. 31, 166 WRV), ${ }^{42}$ contribuyó con éxito a aliviar las demoras que habian sido frecuentes en el procedimiento de control electoral puramente parlamentario de la época imperial.

Además existió el Staatsgerichtshof. Este tribunal no debe confundirse con el Staatsgerichtshof para la Defensa de la República. Este fue un tribunal especial que se creó en 1922 y fue suprimido en 1927 y que debía enjuiciar los delitos previstos en la Ley para la Defensa de la República para combatir las actividades inconstitucionales aprobada tras el asesinato de Walter Rathenau. El citado Tribunal ejerció inadecuadamente sus funciones, de nuevo conforme a una orientación anticomunista. ${ }^{43}$ El Staatsgerichtshof para el Imperio alemán fue, por el contrario, un tribunal previsto en la Constitución con competencias principalmente orientadas al control de los conflictos suscitados entre el Reich y los Länder y éstos entre sí, de las controversias originadas en caso de reorganización del territorio del Reich y subsidiariamente los conflictos surgidos dentro de los Länder, así como las acusaciones dirigidas contra el Presidente, el Canciller y los ministros.

En lo que se refiere al ejercicio de los poderes de excepción del Presidente del Reich, reconoció en principio su competencia de control, pero la ejerció materialmente con gran moderación. Apenas fijó límites al excesivo uso del denominado derecho de excepción. Devaluó la facultad del Reichstag para exigir la derogación de los decretos de excepción al confirmar incondicionalmente la constitucionalidad de la disolución decretada por Hindenburg fundamentada en las exigencias

41 Gertrude Lübbe-Wolff, Der Schutz verfassungsrechtlich verbürgter Individualrechte: Die Rolle des Reichsgerichts, en: Hermann Wellenreuther/Claudia Schnurmann (edits.), Die amerikanische Verfassung und deutsch-amerikanisches Verfassungsdenken, New York/Oxford 1990, pág. 411434; Horst Dreier, Verfassungsgerichtsbarkeit in der Weimarer Republik, en: idem., Staatsrecht in Demokratie und Diktatur, editado por Matthias Jestaedt/Stanley L. Paulson, Tübingen 2016, pág. 59-123 (76 y ss.). Sobre el tribunal de control electoral Stephan Meyer, Das justizförmige Wahlprüfungsgericht beim Reichstag der Weimarer Republik. Institution, Verfahren, Leistung, Berlin 2010, pág. 45. Sobre el apoyo principalmente en círculos antidemocráticos véase entre muchos otros Wolfgang Wehler, Der Staatsgerichtshof für das Deutsche Reich. Die politische Rolle der Verfassungsgerichtsbarkeit in der Zeit der Weimarer Republik, Diss. jur. Bonn 1979, pág. 102 y s., con ulteriores anotaciones

42 Sobre este tribunal, véase más en concreto Meyer, Wahlprüfungsgericht (nota 41).

43 Gotthard Jasper, Der Schutz der Republik. Studien zur staatlichen Sicherung der Demokratie in der Weimarer Republik, Tübingen 1963, pág. 106 y ss., 288 y ss; Gusy, Weimar (nota 39), pág. 345 y ss.; Ingo J. Hueck, Der Staatsgerichtshof zum Schutz der Republik, Tübingen 1996, pág. 134 y ss., 188 y ss., 249 y ss. 
de derogación impuestas por el Reichstag. Avaló, además, el mortal ataque sobre el gobierno y la autonomía del Estado prusiano adoptada el 22 de julio de 1932, autorizando que dicha intervención fuese aprobada, no por la vía de la ejecución federal, sino mediante un decreto de excepción, con el único límite de que su derecho de voto en el Reichsrat no podia ser delegado en un comisario. ${ }^{44}$ Con ello, el Staatsgerichtshof había cavado su propia tumba. Avalados por la decisión del Staatsgerichtshof, los nacionalsocialistas pudieron sincronizar a los Länder que aún eran capaces de actuar. Tras dicha sincronización, los presupuestos de su ejercicio competencial desaparecieron en buena medida.

\section{CONCLUSIÓN}

La Constitución de Weimar se concibió como un Estado democrático. Esta concepción, en atención al modo de formación del gobierno y del rol asumido por el Presidente del Reich, estuvo impregnada de reservas dirigidas contra el demos real y su representación, el Parlamento. Con muchos más reparos la democracia fue interpretada y aplicada en la teoría y en la práctica. La teoría del Estado se mantuvo bastante alejada de los actuales presupuestos de la democracia, incluso por aquellos que defendian la democracia. Probablemente la mayor debilidad del concepto de democracia de la Constitución de Weimar fue el diseño de la figura del Presidente del Reich. A ello contribuyó la desacertada teoría de la división de poderes en la que se apoyó, ajena a una interpretación funcional de las relaciones entre el legislativo y el ejecutivo, la ausencia de una legislación sobre el ejercicio del derecho de excepción del Presidente del Reich y las interpretaciones mantenidas, que acentuaron los problemas. En este caso, como en otros, otras configuraciones constitucionales e interpretaciones alternativas posiblemente hubieran evitado lo peor. Ello no puede afirmarse con total certeza. La relevancia de ocuparse del concepto de democracia en la Constitución de Weimar y de los motivos de su fracaso no reside tanto en su singularidad, sino en poner de manifiesto el significado de la complejidad de las relaciones entre lo jurídico y lo extrajurídico.

Fecha de envío / Submission date: 22/04/2019

Fecha de aceptación / Acceptance date: 5/05/2019

44 En lo que se refiere a las competencias y la judicatura véase en concreto Wehler, Staatsgerichtshof (nota 41); Dreier, Verfassungsgerichtsbarkeit (nota 41), pág. 91 y ss.; Gusy, Weimar (nota 39), pág. 325 y ss. 